\title{
The Swedish Spine Register: development, design and utility
}

\author{
Björn Strömqvist · Peter Fritzell · Olle Hägg · \\ Bo Jönsson · Swedish Society of Spinal Surgeons
}

Received: 22 December 2008/Revised: 6 May 2009/ Accepted: 12 May 2009/Published online: 4 June 2009

(C) The Author(s) 2009. This article is published with open access at Springerlink.com

\begin{abstract}
The Swedish Spine Register enables monitoring of surgical activities focusing on changes in trends over time, techniques utilized and outcome, when implemented in general clinical practice. Basic requirements for a prosperous register are unity within the profession, mainly patient-based documentation and a well functioning support system. This presentation focuses on the development and design of the register protocol, problems encountered and solutions found underway. Various examples on how the results can be presented and utilized are given as well as validation. Register data demonstrate significant gender differences in lumbar disc herniation surgery with females having more pain, lower quality of life and more pronounced disability preoperatively while improvement after surgery is similar between genders. Quality of life after surgery for degenerative disorders is significantly improved for disc herniation, stenosis, spondylolisthesis and disc degenerative disorders. Over the last 10 years, surgical treatment for spinal stenosis has increased gradually while disc herniation surgery decreases regarding yearly number of procedures. An added function to the register enables more complex prospective clinical studies to include register data together with data suitable for the individual study. A common core set of demographic, surgical and
\end{abstract}

\footnotetext{
B. Strömqvist $(\square) \cdot$ B. Jönsson

Department of Orthopedics, Lund University Hospital,

22185 Lund, Sweden

e-mail: bjorn.stromqvist@med.lu.se

P. Fritzell

Department of Orthopedics, Falu Hospital, 79182 Falun,

Sweden

O. Hägg

Göteborg Spine Center, 42130 Gothenburg, Sweden
}

outcome parameters would enable comparisons of clinical studies within and between nations.

Keywords Spine Register - Development .

Degenerative lumbar spine $\cdot$ Core data set

\section{Introduction}

While surgical treatment indications and techniques for defined spinal disorders such as deformities, infections, tumors and fractures are fairly homogenous, the indication for surgical treatment of degenerative disorders mainly is pain which is a subjective experience and difficult to measure. This is the main explanation for the variable incidence of surgical treatment of these disorders [disc herniation, spinal stenosis, spondylolisthesis and degenerative disc disorder (DDD)] between and within nations. Due to shortcomings in outcome and conflicting reports on established techniques $[2,6-8,14]$ an abundance of new implants designed for these disorders (disc and nucleus prostheses, dynamic stabilizers, interspinous spacers, etc) have been introduced in this field of relative surgical indications. Surgical treatment of the described degenerative disorders can today be considered as evidence based, i.e., disc excision for disc herniation, decompression for spinal stenosis, fusion with and without decompression for spondylolisthesis and fusion for DDD. Superiority to nonoperative treatment has been demonstrated in several studies although there is an ongoing debate on whether some specific non-surgical strategies might achieve similar results as surgery on selected patients [7, 8]. Also, the results after surgery are on a level where there are wide margins for improvement. This seems mainly to be related to the indication and patient selection procedure. 
For the newly introduced techniques, a sound basic biomechanical investigation is required followed by pilot human studies and subsequently RCTs comparing them to the "gold standard" today. However, superiority or noninferiority compared to gold standards does not automatically mean that new procedures should on a general basis replace the old procedures. Statistically significant differences do not always imply general medical benefit as individual features and variables have to be taken into account. A second and an as important aspect is that these newly introduced techniques have been performed in specialized centers with high interest in the procedure, adequate skill and often participation in the developmental process. This means that the results achieved cannot automatically be transferred to the results obtained in general utilization of the technique. Thus, the external validity may be less good than a generally high internal validity. For this purpose, wide general registrations of outcomes when the techniques are implemented in clinical practice are mandatory. This is the main reason why broad registration such as a national register is important. Further, a national register makes it possible to monitor indications between regions and over time and also compare outcomes between centers and over time.

The Swedish Spine Register is the first one to emerge and has been in widespread use within our country since 1998. This presentation is aimed at pointing out important features when developing and constructing a register, requirements for implementation and compliance among users and also to demonstrate examples of results achieved to date.

\section{Background and development}

Prospective registration of surgery for degenerative lumbar disorders was initiated in the mid 1980s, at which time such registrations were rare. Results have been presented in the literature [10-13]. At an international conference on the degenerative lumbar spine in 1992, a proposal for national registration was raised and a protocol presented [20]. This protocol was utilized in some Swedish departments during the first 5 or 6 years but did not become widely disseminated. In order to increase participation, the register was transferred to the Swedish Society of Spinal Surgeons and a special task force, the "Register group" consisting of four spinal surgeons and two secretaries was created. In addition to the implementation process, described below, a private consultant in cooperation with the register group developed a register data application named "SweSpine." The register was placed in a private web-hotel outside the health care system in order to facilitate data access under all conditions. This rapidly increased the participation rate in registration and for a decade more than $75 \%$ of all spine departments performing spine surgery have been reporting to the SweSpine. Reports on diagnosis related aggregated data pre-, per- and postoperatively are published each year and are available for the public on the society's homepage: www.4s.nu. From October 2008, results after surgery for disc herniation are available for the public via a homepage. From 2007, the register has also been expanded to include cervical disorders as well as infections, trauma, tumors and deformities, thus creating a register for all spinal surgical problems.

\section{Implementation}

Designing a protocol for registration of spinal disorders might be regarded as a simple task, implementing it on a broad national basis is more complex. Sweden is a small country with respect to inhabitants, 9 millions (although geographically the next biggest in Europe) with about 100 orthopedic surgeons and neurosurgeons performing spine surgery part- or full-time. Thus, it was comparably easy to inform via the Swedish Society for Spinal Surgeons, those involved in Sweden about the register when it was created in the early 1990s. However, in spite of great general enthusiasm and a pronounced interest, only less than 10 of 40 centers in Sweden performing spine surgery participated in the beginning. Analyzing the problems of the register, we identified five problems:

1. The protocol was surgeon-based.

2. The register emanated from one spine center.

3. Lack of support, especially for computer problems was evident as well as lack of on-line support to registering secretaries.

4. Feedback to registering departments was insufficient.

5. Economic support was (and still is) insufficient.

Following this analysis, the following changes were made:

1. The protocol was made entirely patient-based except for information on the surgical procedure.

2. The ownership of the register was transferred to the Swedish Society of Spinal Surgeons. Aggregated data is owned by the society, while each department has disposition of their own data. The board of the society was made responsible for allowing, after a simple request process, researchers to use aggregated data.

3. A private consultant was made responsible for developing the register, and the register was transferred to a private web-hotel (server farm) with $24 \mathrm{~h}$ service, and a support function was created consisting of four spine surgeons and two secretaries. 
4. All registering departments were given access to their data on-line and the possibility to compare them with results of other departments and with the national mean. An annual report from the register was published for the public.

5. Increased economical assistance from the National Board of Health and Welfare was achieved.

These changes were paramount for the success story of the Swedish register; from this period an increasing percentage of the departments performing spine surgery in Sweden participated and the data gathered reflect the nationwide surgical activities on the lumbar spine to a great extent.

\section{Current design}

For degenerative lumbar spine disorders, a preoperative patient-completed protocol contains information on for example smoking, work, sick leave, duration of back and leg pain, consumption of analgesics, walking distance, pain on the VAS scale in the back as well as the leg and the Oswestry Disability questionnaire (ODI) [3], the SF-36 and the EQ-5D. From the beginning the SF-36 questionnaire was utilized, however with the introduction of EQ-5D and the possibility to make health economical calculations it was decided to include this quality of life questionnaire also, in the long run, probably SF-36 will not be used any more. The licensing issue is solved with the Swedish Group of SF-36 [21].

For the added specific disorders, specific parameters such as for example scoliosis angle, fracture and tumor classification are included. The surgical data contain information on diagnosis for and type of surgery, level, side, implant, if used, hospitalization time, antibiotic prophylaxis and complications. The follow-up protocol is mailed to the patient $1,2,5$ and 10 years after surgery and contains the same data as preoperatively plus change in back and leg pain compared to preoperatively and general satisfaction with outcome.

Briefly it seems logical also to mention terminological aspects which may constitute a problem. For example a reoperation for a complication is very obvious but a late reoperation can be performed for a recurrence, for residual symptoms or for a new disease at the same or other spinal levels. Further, a central disc herniation can constitute an indication for disc surgery but also for fusion surgery and in the latter case it may at times from a diagnostic point of view be labeled as disc degenerative disorder/segmental pain as disc herniation patients routinely do not become fused. Such terminological aspects have been the subject of much debate and are clarified in the protocol.
A web-based homepage for patient information has been created and today register data are obtainable on-line both for the profession and for the public. Open comparisons of data from the different departments in Sweden have gradually been introduced from 2008, and also a comparison with national mean parameters. Recently, an addition to the basic register application has been completed, the "SweSpineStudy", which will allow individual departments to compile research data using the register parameters plus other parameters selected at will for the study in question. This will mean that most prospective Swedish studies in the future will have the possibility of having a core data set in common. Studies using register data currently include decompression for spinal stenosis with and without fusion, disc prosthesis vs fusion and others.

\section{Collaboration}

As mentioned previously the Swedish National Board of Health and Welfare (SKL) gives economical funding, and have also created a National Competence Center for Orthopedics (NKO, www.nko.se/en) which is a support function with for example epidemiological and statistical skills that can aid the handling of the register data. Negotiations with the SpineTango, the Eurospine register concerning collaboration have been undertaken. Interest from the other Scandinavian countries in using the Swedish register has been shown and currently Iceland and Denmark are in the process of starting registration with the protocol.

\section{Results}

The following paragraphs show some examples of results from the SweSpine. National data are presented under the name of the Swedish Society of Spinal Surgeons and after application to the Board. Individual departmental data can be analyzed and presented by the individual department. Today the register contains more than 35,000 patients, the majority of which have been operated on for degenerative lumbar spine disorders.

\section{Gender aspects}

More males than females have consistently over time been operated on for disc herniation, isthmic spondylolisthesis, disc degenerative pain and while for spinal stenosis females are dominant [19] (Table 1).

In a study of gender differences in lumbar disc herniation surgery [18], it was demonstrated that significant differences between the genders exist. This study was 
Table 1 Gender vs diagnosis for surgery (percent)

\begin{tabular}{llllll}
\hline & Lumbar disc herniation & Central spinal stenosis & Lumbar spinal stenosis & Spondylolisthesis & Disc degenerative disorder \\
\hline Male & 57 & 44 & 48 & 53 & 53 \\
Female & 43 & 56 & 52 & 47 & 47 \\
\hline
\end{tabular}

performed on a one-center study cohort but the results largely correspond to those of the national data. Before surgery (microscopic or open disc excision), females experienced a higher degree of back pain on the VAS scale (Fig. 1a) while no difference was noticed regarding leg pain. Disability (ODI) was preoperatively more pronounced for females than males (Table 2) and quality of life significantly lower on several domains (vitality, general health, mental health) according to the SF-36. Other baseline parameters such as duration of pain, smoking and walking distance did not differ. Smokers of both genders were overrepresented compared to national figures among those subjected to disc surgery.
The relative improvement measured 1 year after surgery was similar between the genders and satisfaction with outcome of surgery identical (Table 3). However, this degree of improvement meant that back pain (Fig. 1b), leg pain (Fig. 2) disability and some aspects of quality of life (vitality, physical function, bodily pain) still were inferior among females at the 1-year follow-up (Fig. 3).

These findings would suggest that there might be a difference between genders regarding proneness to undergo surgery for lumbar disc herniation, differences between the genders in reaction to low back pain/sciatica or differences in the selection for surgery process. It might be notable that the vast majority of spine surgeons in Sweden are male.
Fig. 1 Back pain on the VAS scale before (a) and 1 year after (b) surgery related to gender

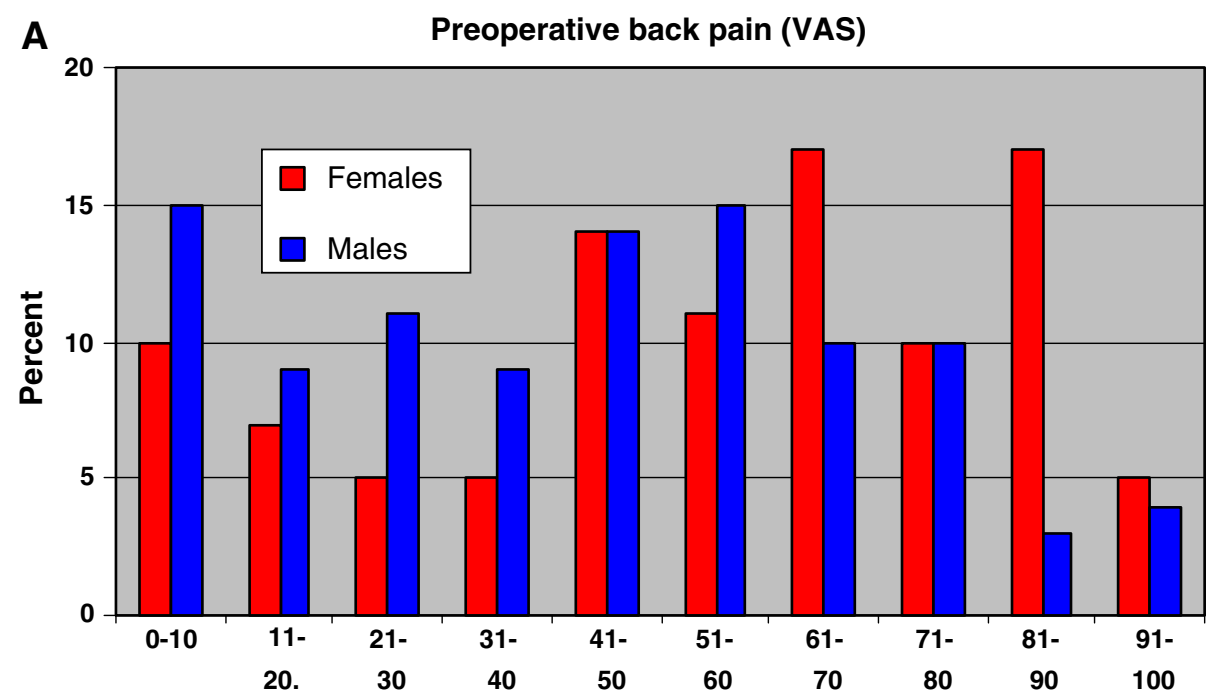

B

Postop back pain (VAS)

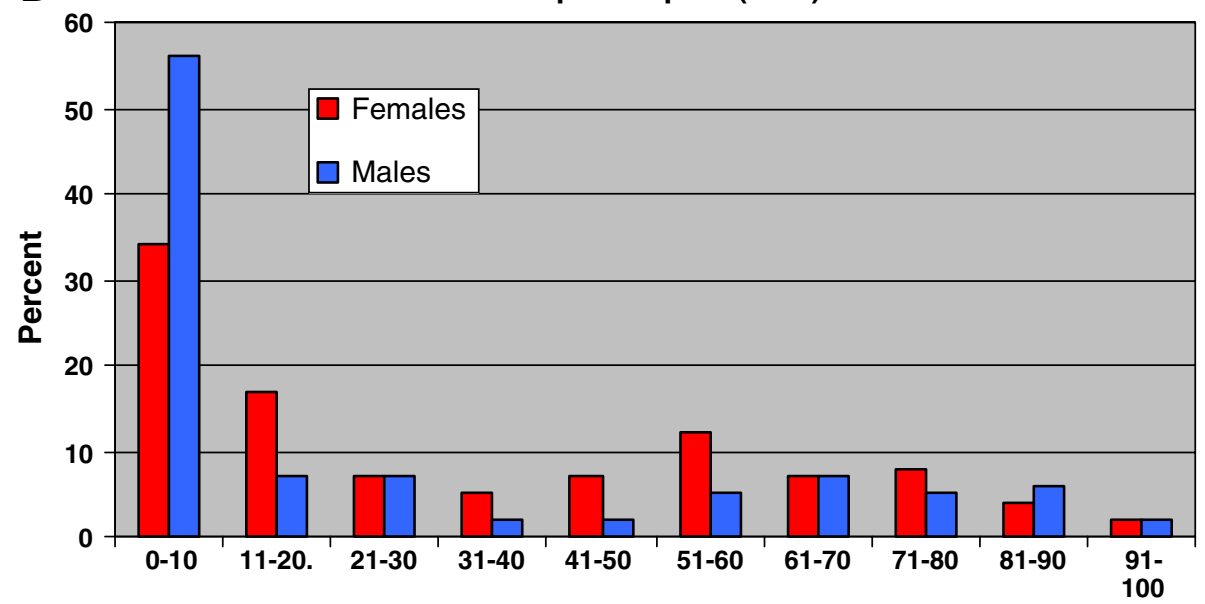


Table 2 Gender vs disability (ODI mean, median, range) before and after surgery for lumbar disc herniation (Fairbank 00)

\begin{tabular}{lllllllll}
\hline & \multicolumn{2}{l}{ Preoperatively } & & & \multicolumn{3}{c}{ year postoperatively } \\
\cline { 2 - 3 } & Mean & Median & Range & & Mean & Median & Range \\
\hline Male & 45 & 40 & $(1-86)$ & 15 & 4 & $(0-86)$ \\
Female & 55 & 51 & $(4-96)$ & 26 & 22 & $(1-82)$ \\
\hline
\end{tabular}

Scale 0-100, high value high disability, 0-20 minimal or no disability

Table 3 Satisfaction with outcome of surgery for lumbar disc herniation (percent)

\begin{tabular}{lllc}
\hline & Satisfied & Undecided & Dissatisfied \\
\hline Male & 73 & 19 & 8 \\
Female & 70 & 19 & 11 \\
\hline
\end{tabular}

The differences encountered form the basis for further analysis.

\section{Surgical treatment for DDD}

Disc degenerative disease, DDD or segmental pain is not a strictly specific spine disorder. Asymptomatic disc degeneration is seen from the 2 nd or 3rd decade of life and is very common in elderly; disc degeneration is a normal physiological aging process. However, in a limited number of cases, this degeneration may elicit pronounced mechanical low back pain without or with limited radiation to the leg/legs. There is a significant debate on the value of treating DDD surgically but evidence suggesting its value exists [5]. The patient group described may experience this low back pain as a primary disorder or it might the sequelae of a lumbar disc herniation, whether or not treated surgically. This patient group is more or less the same as the group proposed to be treated by the disc prostheses today. Therefore, it is of interest to see how these patients are treated on a national basis today, there seems to be unity of the requirement that before surgery at least a 6-months period of active rehabilitation should be applied.

There is also a debate on what type of fusion that should be used in these cases. Several investigations point at noninstrumented fusion to perform as well as more complex instrumented procedures which, as such, carry a higher complication rate but also one investigation pointing at $360^{\circ}$ of fusion to give a better long-term outcome has been presented [17].

The figures from the national register on the type of surgery for DDD are presented in Table 4. It is obvious from the data that there is not a unity on which treatment should be applied within Sweden, and it is also obvious that disc prostheses are beginning to be more frequently utilized for these patients. In spite of published data speaking for the use of non-instrumented fusion [5, 6, 22], today only $4 \%$ of the operations use this modality (Table 4 ). This certainly may be a hot topic when register data is more widely distributed and analyzed in the society. The register gives a good possibility to monitor changes in surgical preferences and techniques over time.

\section{Length of follow-up}

In 1987, the Quebec Task Force established the follow-up time required for scientific studies on lumbar spine surgery to be minimum 2 years. This has thereafter become a requirement for studies to be accepted for publication in peer reviewed journals. One argument is that deterioration may not be uncommon during the second year after surgery, and for large surgical procedures, the outcome might be difficult to define at a 1-year follow-up. Most
Fig. 2 Leg pain on the VAS scale 1 year after surgery related to gender

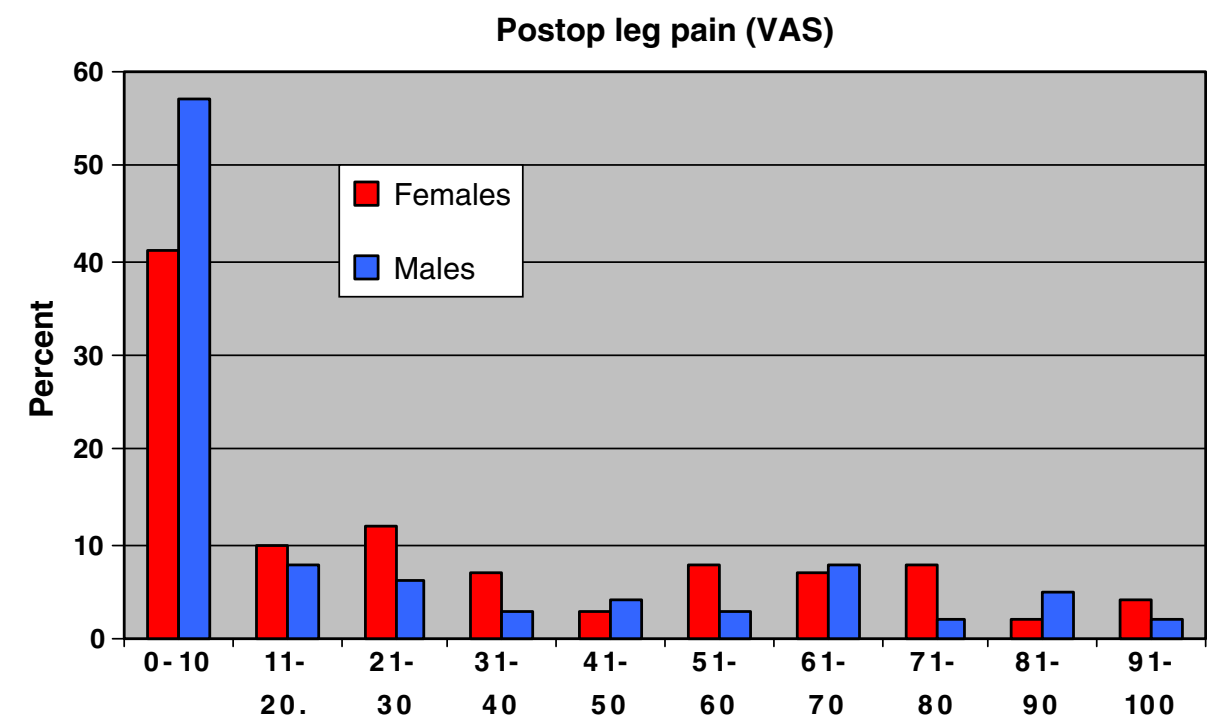




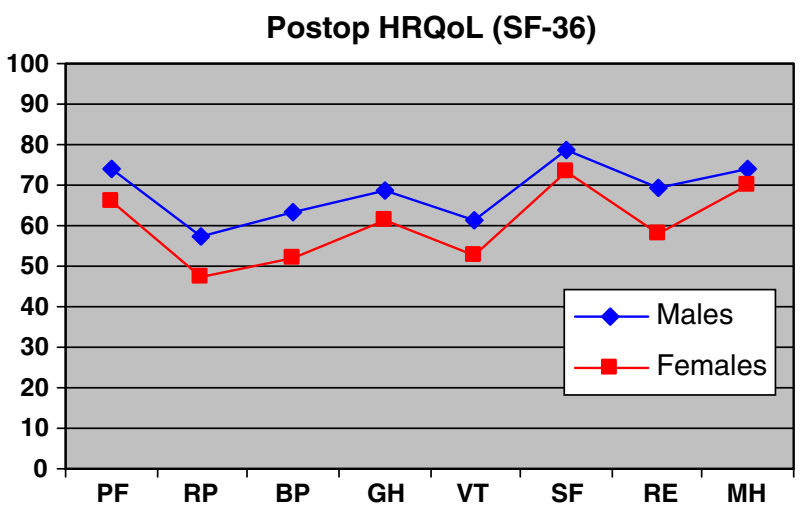

Fig. 3 SF-36 scores 1 year after surgery for LDH, according to gender

re-operations are performed within the first year and thereafter occur with decreasing frequency.

In limited prospective studies, therefore, a 2-year follow-up might be of a higher value than a 1-year follow-up. However, for large studies such as the register, the results at 1,2 and also preliminarily 5 years after surgery are more or less identical for disc herniation, stenosis, spondylolisthesis and DDD (Table 5). This therefore would question the general need for longer follow-up and would enable prospective studies to be presented earlier.

Quality of life before and after spine surgery

For disc herniation, spinal stenosis, isthmic spondylolisthesis and DDD, a common feature is a very low preoperative quality of life which has been demonstrated by the SF-36 as well as the EQ-5D. The preoperative EQ-5D figures vary from 0.20 to 0.35 for all groups of patients in the register (Fig. 4). A dramatic increase is seen after surgery for all diagnoses treated, most pronounced in disc herniation (Fig. 4). These figures are retained at 2 years postoperatively and the relative gain in quality of life for lumbar spine patients is for example higher than that of knee arthroplasty and almost on a par of that of hip arthroplasty [16].

\section{Trends over time}

Over the last 10 years, the relative number of lumbar disc herniation surgery has gradually decreased while spinal stenosis surgery is increasing (Fig. 5). For DDD there is also a slow increase in number of procedures yearly. Also in this respect, the national register gives an eminent possibility to monitor changes in trends over time (Fig. 6).

\section{Validation of register data}

The patient register in Sweden used by the authorities (Patientregistret), is based on ICD10, and reported by the departments to the National Board of Health and Welfare (Socialstyrelsen), each year. Here all surgical interventions are included. By comparing these figures with figures from "SweSpine", it is possible to get a fair impression how the different departments manage to report to the register. Also, by comparing the actual catchment area for each department, it is possible to discuss the registration profile of each department. Today, at least $75 \%$ of all surgical procedures are reported to SweSpine, although there is a difference among departments. To optimize registration and follow-up is the current most important task for the society. In order to facilitate this, a certain function has been included in the register, automatically giving the registering department notion on when to send follow-up questionnaires to the individual patient.

The register protocol has been subjected to a test-retest analysis [25] documenting adequate reliability.

Table 4 Type of surgery (percent) performed for Degenerative Disc Disease, DDD, over time (1999-2007)

\begin{tabular}{|c|c|c|c|c|c|}
\hline Type of surgery & $1999 \%$ & $2001 \%$ & $2003 \%$ & $2005 \%$ & $2007 \%$ \\
\hline Posterolateral instrumented fusion & 45 & 34 & 20 & 24 & 19 \\
\hline ALIF with/without implants & 22 & 14 & 5 & 4 & 1 \\
\hline PLIF & 0 & 18 & 31 & 26 & 20 \\
\hline Disc prosthesis & 1 & 0 & 11 & 10 & 20 \\
\hline Decompression + PLIF & 0 & 0 & 8 & 7 & 9 \\
\hline Decompression + posterolateral instrumented fusion & 15 & 16 & 9 & 7 & 9 \\
\hline Posterolateral uninstrumented fusion & 11 & 3 & 6 & 7 & 4 \\
\hline Nucleus prosthesis & 0 & 0 & 1 & 0 & 0 \\
\hline TLIF & 0 & 0 & 0 & 4 & 7 \\
\hline Total number of patients & & & & & \\
\hline
\end{tabular}


Table 5 Diagnosis related satisfaction with outcome of surgery at 1,2 and 5 years postoperatively

\begin{tabular}{|c|c|c|c|c|c|c|c|c|c|}
\hline & \multicolumn{3}{|l|}{1 year } & \multicolumn{3}{|l|}{2 years } & \multicolumn{3}{|l|}{5 years } \\
\hline & Satisfied & Undecided & Dissatisfied & Satisfied & Undecided & Dissatisfied & Satisfied & Undecided & Dissatisfied \\
\hline $\mathrm{LDH}$ & 75 & 17 & 8 & 76 & 16 & 8 & 77 & 15 & 8 \\
\hline $\mathrm{CS}$ & 63 & 24 & 13 & 62 & 24 & 14 & 61 & 23 & 16 \\
\hline LS & 60 & 24 & 16 & 59 & 24 & 17 & 56 & 27 & 18 \\
\hline Spond & 70 & 21 & 9 & 72 & 18 & 10 & 70 & 20 & 11 \\
\hline DDD & 66 & 23 & 11 & 66 & 22 & 13 & 66 & 18 & 15 \\
\hline
\end{tabular}

Fig. 4 Diagnosis-related change in EQ-5D 1 and 2 years after surgery as compared to preoperatively related to diagnosis

Fig. 5 Diagnosis for surgery 1998-2007 (\%)

\section{Quality of life reported by 655 patient operated for different spinal disorders, \\ Euroqol (EQ-5D) \\ $100=$ optimal quality of life $0=$ equals "death"}

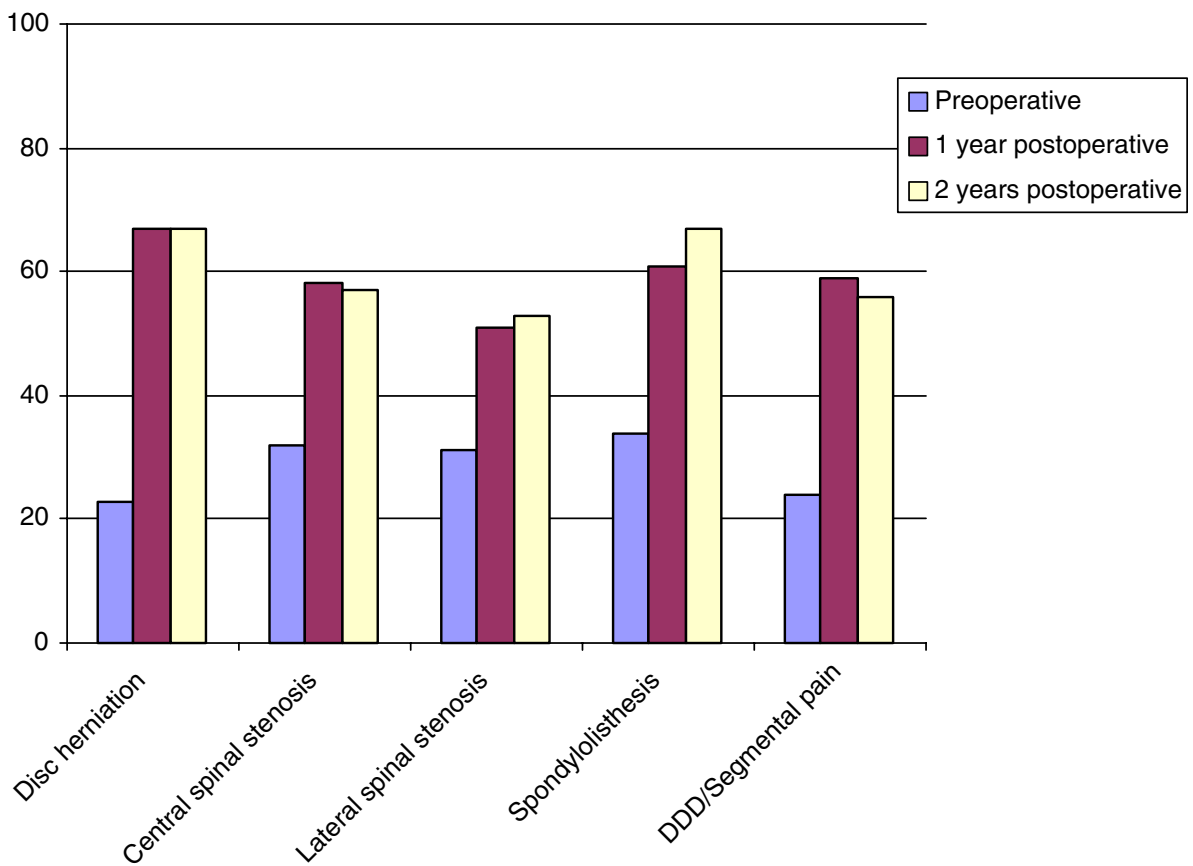




Fig. 6 Type of surgery (percent) performed for Degenerative Disc Disease, DDD, over time (1999-2007)

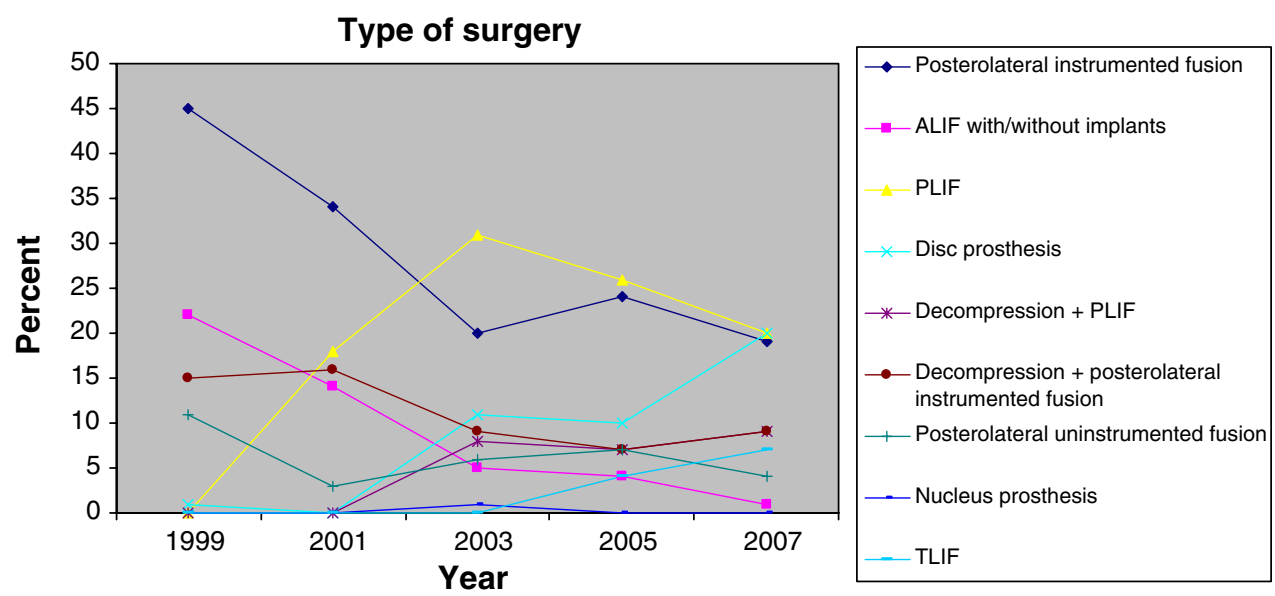

\section{Discussion}

This presentation has aimed at describing the evolution of the national Swedish Spine Register, problems encountered and solutions found during its growth. We have also described the design of the protocol today and given examples of how registered data can be fruitful.

For the most common indications for lumbar spine surgery, disc herniation and spinal stenosis, surgery has historically proven useful in many studies, although adequate comparative studies with non-operative treatment are generally lacking. The classical study by Weber [23], which only hinted at a short-term benefit of lumbar disc herniation surgery, is hampered by the fact that $1 / 3$ of the patients were operated on for "severe symptoms" before the randomization process was undertaken. A study on the long-term natural course of lumbar spinal stenosis [9] showed that the natural course of untreated stenosis often is benign but the patients assigned to the study of the natural course follow-up were not randomly provided.

The large SPORT study [24] compares surgical and nonsurgical treatment of both disorders and shows the effect of surgery but with a very high number of group changers in both groups.

For isthmic spondylolisthesis and DDD, RCTs comparing surgical and non-surgical treatment exist today $[1,4$, $5,14]$ and, although the results are to some extent conflicting, these diagnoses can be said to be exponents for evidence-based medicine, EBM. Still there is a significant need to improve patient selection in order to achieve better outcomes.

Surgery of the degenerative disorders of the lumbar spine is generally favorable as regards improvement of quality of life, and gold standards, with which new techniques or procedures should be compared may be said to exist. When implementing a new surgical technique, if an implant is involved, biomechanical investigations must be properly performed before their use. After that, pilot studies demonstrating the feasibility of the implant must be carried out and, logically, the next step is an RCT comparing it to the gold standard. However, it has to be noted that even with an RCT showing superior results for the new implant, this firstly does not imply that the new implant should replace the old technique generally, but multivariate analyses might demonstrate where it is superior, and secondly, the new implant has to show its value in general practice. In an RCT, normally a limited number of specialized centers with devoted surgeons are performing the operations, and the results obtained are not necessarily those of the general spine orthopedic or neurosurgical surgeon, i.e., in spite of high internal validity, the external validity is more limited meaning that the results are not generalizable. It is for this latter purpose, that wide registrations such as national registers are of utmost importance, and they may well be used for identifying implants performing inferiorly.

Basically, it is mandatory in a national register to be as complete as possible and to avoid lack of follow-up. This is facilitated by using patient based questionnaires regarding pre- and postoperative data. Specific problems in addition to completeness of follow-up may be complication registration and it is of utmost importance to make double-check follow-ups. In addition to the surgeon-based specified complication registration in the Swedish register, the patient is also asked to report complications at 1-year follow-up which should reduce the risk for incompleteness of data.

Another important issue is to make the register participants able and motivated. The support function is in our opinion mandatory for enabling the individual departments to register their data and it has been met with high appreciation from the participants regularly. Problems and questions may be solved immediately by telephone correspondence, email, or also visits at the individual departments.

Feedback is another matter of high importance. From using a yearly report of register data, we have been able to 
allow the individual participants to study their data and aggregated register data on-line during the last 3 years and also to compare their data with the national mean and the data of other departments. This makes register data much more valuable for the individual patient, and also gives automatic quality assurance.

The register has received yearly funding from the National Board of Health and Welfare, without which the register would not exist today. However, the funding is not sufficient to keep the register running but the individual departments have to have specific contact secretaries and contact surgeons responsible for data retrieval. This means that some costs are put on the registering individual department. This could be a problem in the past but today the general awareness of the need of quality management is high and we see currently no problems in this respect.

Recent improvements for the register are firstly the inclusion of all types of disorders of the spine and all parts of the spine, i.e., cervical, thoracic and lumbar spine, making the register complete. Elaborating this, about 20 Swedish spine surgeons have taken part in making a product which is possible to use since 2006. Secondly, a possibility to expand register data with specific data for individual research studies has been added "SweSpineStudy" and several ongoing projects are using the facilities of the register in RCTs.

The level of openness in presenting register data has been discussed to a great extent. Until recently, only representatives for the individual department could see their own data per se and compared to the national mean. However, it is a strong political issue to provide comparison on departmental or even on physician levels. At present, the results for individual departments can be compared openly and department related results on disc herniation surgery have been presented [15]. What influence this will have on future spine surgery is not obvious yet. Competition for spine patients is not high today as there is a relative deficiency of spine surgery capacity. This might prove quite different in the future.

Recently other countries have shown interest in using the register, with Denmark and Iceland being the first to achieve the application. This is in line with the intention of the society, as the analysis interpretation is that the more departments that use the same register platform with a core data set, the easier it will become to make broad and valid comparisons both on a national and an international level, which will be to the benefit of all involved parties.

\section{Conclusion}

The development, design and data presentation from the National Swedish Spine Register, SweSpine, have been
Table 6 Suggestion for core data set in degenerative lumbar spine surgery

\begin{tabular}{|c|c|}
\hline & Category \\
\hline \multicolumn{2}{|l|}{ Preoperative data } \\
\hline \multicolumn{2}{|l|}{ Age } \\
\hline Sex & Male/female \\
\hline Smoking habits & Yes/no \\
\hline Working ability & $\begin{array}{l}\text { Full-time/part-time/sick leave/ } \\
\text { unemployed }\end{array}$ \\
\hline Consumption of analgesics & Regular/Intermittent/None \\
\hline Walking distance & $\begin{array}{l}<100 \mathrm{~m} / 100-500 \mathrm{~m} / 0.5-1 \mathrm{~km} / \\
>1 \mathrm{~km}\end{array}$ \\
\hline Duration of current problem & $\begin{array}{l}<3 \text { months } / 3-12 \text { months/ } 1-2 \text { years/ } \\
>2 \text { years }\end{array}$ \\
\hline Back pain (VAS) & $0-100 \mathrm{~mm}$ \\
\hline Leg pain (VAS) & $0-100 \mathrm{~mm}$ \\
\hline EQ-5D & $0-1$ \\
\hline Oswestry Disability Index & $0-100$ \\
\hline \multicolumn{2}{|l|}{ Surgical data } \\
\hline Diagnosis for surgery & $\begin{array}{l}\mathrm{LDH} / \text { central stenosis/lateral stenosis/ } \\
\text { isthmic spondylolisthesis/DDD }\end{array}$ \\
\hline Operation performed & 20 specified types \\
\hline Level & Upper-lower level \\
\hline Side & R/L/bilat/NA \\
\hline Implant & According to implant list \\
\hline \multicolumn{2}{|l|}{ Hospitalization time } \\
\hline Complication & Yes/no type \\
\hline $\begin{array}{l}\text { Re-operation for } \\
\text { complication }\end{array}$ & Yes/no type \\
\hline \multicolumn{2}{|l|}{ Postoperative data } \\
\hline Working ability & $\begin{array}{l}\text { Full-time/part-time/sick leave/ } \\
\text { unemployed }\end{array}$ \\
\hline Consumption of analgesics & Regular/intermittent/none \\
\hline Walking distance & $\begin{array}{l}<100 \mathrm{~m} / 100-500 \mathrm{~m} / 0.5-1 \mathrm{~km} / \\
>1 \mathrm{~km}\end{array}$ \\
\hline Back pain (VAS) & $0-100 \mathrm{~mm}$ \\
\hline Leg pain (VAS) & $0-100 \mathrm{~mm}$ \\
\hline EQ-5D & $0-1$ \\
\hline Oswestry Disability Index & $0-100$ \\
\hline $\begin{array}{l}\text { Improvement of back pain } \\
\text { compared to preoperative }\end{array}$ & $\begin{array}{l}\text { Abolished/significantly improved/ } \\
\text { somewhat improved/unchanged/ } \\
\text { worsened }\end{array}$ \\
\hline $\begin{array}{l}\text { Improvement of leg pain } \\
\text { compared to preoperative }\end{array}$ & $\begin{array}{l}\text { Abolished/significantly improved/ } \\
\text { somewhat improved/unchanged/ } \\
\text { worsened }\end{array}$ \\
\hline $\begin{array}{l}\text { General satisfaction with } \\
\text { outcome of surgery }\end{array}$ & Satisfied/uncertain/dissatisfied \\
\hline
\end{tabular}

described. Concerning the logistics we feel that striving for simplicity together with a patient-based protocol, on-line reporting and on-line support are mandatory for success. The ownership by the Swedish Society of Spinal Surgeons is important for its dissemination and the on-line access of 
the individual department to relevant data is a prerequisite for clinical use of the register. Completeness of data is mandatory and this is continuously monitored. Dependency on secretaries rather than surgeons increases the possibility for completeness.

With these aspects taken into consideration, register data can serve as an excellent monitoring of surgical activities, observing changes in trends regarding indications, techniques utilized and outcome. The results presented above are merely some examples of the possibilities of gathering information from the register. We appreciate all interest in international collaboration and we believe that a common "core set" of data (Table 6) could be created enabling the comparison of results internationally and especially within Europe.

Acknowledgments The devoted work of register secretaries Carina Blom and Lena Oreby has been and still is invaluable. The loads of works and efforts from spine surgeons and register secretaries at the participating departments within Sweden are significant and a prerequisite for the data presented. The spine surgeons participating in creating the protocols are also to be highlighted. Finally, the economical funding from the National Board of Health and Welfare/SKL is acknowledged.

Open Access This article is distributed under the terms of the Creative Commons Attribution Noncommercial License which permits any noncommercial use, distribution, and reproduction in any medium, provided the original author(s) and source are credited.

Conflict of interest statement None of the authors has any potential conflict of interest.

\section{References}

1. Brox JI, Sørensen R, Friis A, Nygaard Ø, Indahl A, Keller A, Ingebrigtsen T, Eriksen HR, Holm I, Koller AK, Riise R, Reikerås O (2003) Randomized clinical trial of lumbar instrumented fusion and cognitive intervention and exercises in patients with chronic low back pain and disc degeneration. Spine 28:19131921. doi:10.1097/01.BRS.0000083234.62751.7A

2. Christensen FB, Hansen ES, Eiskjaer SP, Høy K, Helmig P, Neumann P, Niedermann B, Bünger CE (2002) Circumferential lumbar spinal fusion with Brantigan cage versus posterolateral fusion with titanium Cotrel-Dubousset instrumentation: a prospective, randomized clinical study of 146 patients. Spine 27:2674-2683. doi:10.1097/00007632-200212010-00006

3. Fairbank JC, Pynsent PB (2000) The Oswestry Disability Index. Spine 25:2940-2952. doi:10.1097/00007632-200011150-00017 discussion 2952

4. Fairbank J, Frost H, Wilson-MacDonald J, Yu LM, Barker K, Collins R, Spine Stabilisation Trial Group (2005) Randomised controlled trial to compare surgical stabilisation of the lumbar spine with an intensive rehabilitation programme for patients with chronic low back pain: the MRC spine stabilisation trial. BMJ 330:1233. doi:10.1136/bmj.38441.620417.8F

5. Fritzell P, Hägg O, Wessberg P, Nordwall A, Swedish Lumbar Spine Study Group (2001) 2001 Volvo Award Winner in Clinical Studies: lumbar fusion versus nonsurgical treatment for chronic low back pain: a multicenter randomized controlled trial from the Swedish Lumbar Spine Study Group. Spine 26:2521-2532. doi: 10.1097/00007632-200112010-00002 discussion 2532-2534

6. Fritzell P, Hägg O, Wessberg P, Nordwall A, Swedish Lumbar Spine Study Group (2002) Chronic low back pain and fusion: a comparison of three surgical techniques: a prospective multicenter randomized study from the Swedish lumbar spine study group. Spine 27:1131-1141. doi:10.1097/00007632-200206010-00002

7. Ha KY, Na KH, Shin JH, Kim KW (2008) Comparison of posterolateral fusion with and without additional posterior lumbar interbody fusion for degenerative lumbar spondylolisthesis. J Spinal Disord Tech 21:229-234. doi:10.1097/BSD.0b01 3e3180eaa202

8. Harrington JF, French P (2008) Open versus minimally invasive lumbar microdiscectomy: comparison of operative times, length of hospital stay, narcotic use and complications. Minim Invasive Neurosurg 51:30-35. doi:10.1055/s-2007-1004543

9. Johnsson KE, Udén A, Rosen I (1992) The natural course of lumbar spinal stenosis. Clin Orthop Relat Res 279:82-86

10. Jönsson B, Strömqvist B (1993) Symptoms and signs in degeneration of the lumbar spine. A prospective, consecutive study of 300 operated patients. J Bone Joint Surg Br 75-B:381-385

11. Jönsson B, Strömqvist B (1993) Repeat decompression of lumbar nerve roots. A prospective two-year evaluation. J Bone Joint Surg Br 75-B:894-897

12. Jönsson B, Strömqvist B (1994) Lumbar spine surgery in the elderly. Complications and surgical results. Spine 19:1431-1435

13. Jönsson B, Sjöberg C, Annertz M, Strömqvist B (1997) A prospective and consecutive study of surgically treated lumbar spinal stenosis. Part II: Five-year follow-up by an independent observer. Spine 22:2938-2944. doi:10.1097/00007632-199712150-00017

14. Möller H, Hedlund R (2000) Instrumented and noninstrumented posterolateral fusion in adult spondylolisthesis - a prospective randomized study: part 2. Spine 25:1716-1721. doi:10.1097/ 00007632-200007010-00017

15. (2008) Open comparisons of quality and efficiency of health care (Öppna jämförelser av hälso- och sjukvårdens kvalitet och effektivitet. Jämförelser mellan landsting). ISBN 978-91-7164-387-2

16. Rampersaud YR, Ravi B, Lewis SJ, Stas V, Barron R, Davey R, Mahomed N (2008) Assessment of health-related quality of life after surgical treatment of focal symptomatic spinal stenosis compared with osteoarthritis of the hip or knee. Spine J 8:296304. doi:10.1016/j.spinee.2007.05.003

17. Soegaard R, Bünger CE, Christiansen T, Høy K, Eiskjaer SP, Christensen FB (2007) Circumferential fusion is dominant over posterolateral fusion in a long-term perspective: cost-utility evaluation of a randomized controlled trial in severe, chronic low back pain. Spine 32:2405-2414. doi:10.1097/BRS. 0b013e3181573b2d

18. Strömqvist F, Ahmad M, Hildingsson C, Jönsson B, Strömqvist B (2008) Gender differences in lumbar disc herniation surgery. Acta Orthop 79:643-649. doi:10.1080/17453670810016669

19. Strömqvist B, Fritzell P, Hägg O, Jönsson B (2005) One-year report from the Swedish National Spine Register. Swedish Society of Spinal Surgeons. Acta Orthop 76(Suppl 319):1-24. doi:10.1080/17453690510041950

20. Strömqvist B, Jönsson B (1993) Computerized follow-up after surgery for degenerative lumbar spine diseases. Acta Orthop Scand 64(Suppl 251):138-142

21. Sullivan M, Karlsson J, Ware JE (1994) Hälsoenkät SF-36. Svensk manual och tolkningsguide 1994. (SF-36 Health survery. Swedish manual and interpretation guide). Sahlgrenska University Hospital, Göteborg

22. Thomsen K, Christensen FB, Eiskjaer SP, Hansen ES, Fruensgaard S, Bünger CE (1997) 1997 Volvo Award winner in clinical studies. The effect of pedicle screw instrumentation on functional 
outcome and fusion rates in posterolateral lumbar spinal fusion: a prospective, randomized clinical study. Spine 22:2813-2822. doi: 10.1097/00007632-199712150-00004

23. Weber H (1983) Lumbar disc herniation. A controlled, prospective study with ten years of observation. Spine 8:131-140. doi: 10.1097/00007632-198303000-00003

24. Weinstein JN, Tosteson TD, Lurie JD, Tosteson AN, Hanscom B, Skinner JS, Abdu WA, Hilibrand AS, Boden SD, Deyo RA
(2006) Surgical vs nonoperative treatment for lumbar disk herniation: the Spine Patient Outcomes Research Trial (SPORT): a randomized trial. JAMA 22(296):2441-2450. doi:10.1001/ jama.296.20.2441

25. Zanoli G, Nilsson LT, Strömqvist B (2006) Reliability of the prospective data collection protocol of the Swedish Spine Register. Test-retest analysis of 119 patients. Acta Orthop 77:662669. doi:10.1080/17453670610046064 